\title{
O Sofrimento Psíquico no Trabalho de Vigilância em Prisões
}

Mental Suffering in Prison Surveillance Work

El Sufrimiento Psíquico en el Trabajo de Vigilancia en Prisiones

Cassiano Ricardo Rumin, Gislaine Ilsiméia Faria Barros, Willian Rogério Cardozo \& Roseli Cavalhero Faculdades Adamantinenses Integradas 
Resumo: Este relato de experiência profissional apresenta características do sofrimento psíquico vivenciado por agentes de segurança penitenciária (ASPs) e delimita os elementos psicodinâmicos que emergem no trabalho de vigilância prisional. A partir de um espaço para o acolhimento desses trabalhadores, pôde-se apreender: o esvaziamento do sentido do trabalho, a sensação de enclausuramento em algumas funções, a temerosidade em relação à segurança e a representação social pejorativa desse trabalho. A atenção em saúde mental permitiu a compreensão de vivências ansiogênicas, a elaboração dos aspectos psicodinâmicos mobilizados pelas exigências institucionais e ainda propiciou a mobilização subjetiva para o enfrentamento das práticas disciplinares institucionais.

Palavras-chave: Saúde do trabalhador. Saúde mental. Trabalho. Prisões.

Abstract: This professional experience report presents characteristics of mental suffering experienced by prison security agents (PSAs) and outlines the psychodynamic elements that emerge in prison surveillance work. Based on a space for mental health care delivery to these workers, the following factors were apprehended: the emptiness of the work meaning, the feeling of imprisonment in some functions, the fearfulness about the security and the pejorative social representation of this work. This mental health care allowed the understanding of anxiogenic experiences, the elaboration of the psychodynamic aspects mobilized by institutional demands and it also favored subjective mobilization for coping with institutional disciplinary practices.

Keyword: Worker's health. Mental health. Work. Prisons.

Resumen: Este relato de experiencia profesional presenta características del sufrimiento psíquico vivido por Agentes de Seguridad Penitenciaria (ASPs) y delimita elementos psicodinámicos que emergen en el trabajo de vigilancia de prisiones. A partir de un espacio para la acogida de estos trabajadores se puede aprender: cómo el sentido del trabajo se torna vacío; la sensación de enclaustramiento en algunas funciones; temores en relación a la seguridad y la representación social peyorativa de este trabajo. La atención en salud mental permitió la comprensión de vivencias antigénicas y la elaboración de los aspectos psicodinámicos movilizados por las exigencias institucionales. Asimismo, propició la movilización subjetiva para el enfrentamiento de las prácticas disciplinarias institucionales.

Palabras clave: Salud del trabajador. Salud mental. Trabajo. Prisiones.

A partir de 1980, mudanças na estrutura pública e privada de ocupação da mão de obra trabalhadora determinaram novos processos de gestão e organização do trabalho que se expressam na flexibilização do trabalho, na sua precarização e no desemprego estrutural (Antunes \& Alves, 2004). Nesse contexto, gradualmente ganham destaque as discussões relacionadas ao desencadeamento do adoecimento e do sofrimento psíquico originados nas relações de trabalho.

Codo e Jacques (2002) afirmam que o sofrimento psíquico e a doença mental ocorrem quando o trabalho afeta esferas de nossas vidas que são geradoras e transformadoras de significados. Assim, existiriam fatores nocivos no trabalho representados pelas condições de execução, pela sua organização e pelas relações simbólicas mediadas pela ação produtiva.
Entende-se que o sofrimento psíquico pode se manifestar em articulações entre a singularidade dos afetos individuais e a coletividade, tal como nos espaços sociais originados das ações produtivas. Nessa perspectiva, as instituições prisionais reúnem situações adversas que expõem os trabalhadores ao acirramento do sofrimento psíquico, tais como relações hierárquicas rígidas, contato cotidiano com a violência, trabalho em espaços confinados, divisão em turnos e prejuízos à percepção de ressonância simbólica no trabalho.

O presente trabalho apresenta uma experiência desenvolvida em uma prática profissionalizante supervisionada em Psicologia realizada em uma unidade prisional de regime fechado da região oeste do Estado de São Paulo. Trata-se de um estabelecimento penal de segurança máxima, destinado ao cumprimento de pena privativa de liberdade 
por sentenciados do sexo masculino. Existe, ainda, uma ala de progressão para abrigar os sentenciados que alcançaram o benefício de progressão penal enquanto aguardam vagas para transferência para os Centros de Progressão Penitenciária (CPP).

Após a caracterização das condições de trabalho na segurança penitenciária (Rumin, 2006), efetivou-se a criação de um espaço de acolhimento ao sofrimento psíquico. Esse espaço estava inserido na rotina de trabalho da unidade prisional de segurança máxima. Desse modo, pode-se considerar que o contato com o "discurso subjetivo do trabalho" (Dejours, 1999a) ofertaria contribuições ao conhecimento dos fenômenos psicodinâmicos que pudessem emergir em decorrência da execução de atividades produtivas nas instituições prisionais.

\section{Metodologia}

Com o intuito de oferecer atenção em saúde mental, foi constituído um espaço de acolhimento ao sofrimento originado pelas relações de trabalho na vigilância penitenciária. Os trabalhadores recebiam a atenção em saúde mental em encontros individuais que foram estabelecidos em modelo de plantões durante a jornada de trabalho. A expressão discursiva foi analisada pelo método psicanalítico de orientação breve.

Braier destaca que a utilização da psicoterapia breve como técnica de intervenção deve considerar que "a solução dos problemas imediatos e o alívio sintomático deverão, em um sentido psicodinâmico, corresponder à obtenção de um princípio de insight do paciente a respeito dos conflitos subjacentes" (2000, p. 19). A escuta realizada nesse espaço permitiu a apreensão de vivências coletivas e individuais conjugadas ao processo de trabalho.
Conforme Codo (2004), a expressão discursiva sobre o sofrimento psíquico no trabalho pode ser traduzida por métodos associativos nas diversas formas e circunscrições onde as vivências conflituosas se expressam. Desse modo, estabelecia-se uma ação de catálise de afetos que propiciava a representação do passado, da situação atual e das perspectivas futuras. Assim, a elaboração de representações forneceria suporte à constituição identitária dos trabalhadores, contribuindo para a manutenção da sua saúde mental (Herrmann, 2001).

\section{O contexto de trabalho e os referenciais teóricos para a compreensão do discurso dos trabalhadores}

Os trabalhadores da unidade prisional abordada neste trabalho são alocados em turnos de trabalho com escalas de 12 horas de atividade, com descanso que perdura por 36 horas. Nesse sistema estão envolvidos os agentes de segurança penitenciária (ASPs) e os agentes de escolta e vigilância penitenciária (AEVPs). Existem, ainda, os diaristas que trabalham durante a semana em escalas de 8 horas diárias, tais como os oficiais administrativos, profissionais de saúde e de manutenção da unidade prisional.

As concepções de Dejours (1994, 1999a, 1999b) e de Käes $(1991,2005)$ foram utilizadas para a compreensão do discurso dos trabalhadores. Assim, foram observados elementos psicodinâmicos que permitiam aos trabalhadores organizar seu cotidiano mesmo na presença de intenso sofrimento. Dejours (1994, 1999a, 1999b) esforça-se por compreender o modo como as estratégias defensivas coletivas são mobilizadas para distanciar o trabalhador das manifestações de adoecimento. Nesse sentido, considerase que o sofrimento psíquico pode conduzir o trabalhador à doença, conforme as 
possibilidades de uma efetiva negociação entre seus desejos e as exigências laborais. $\mathrm{O}$ autor designa o sofrimento como "o campo que separa a doença da saúde" (1994, p.15).

A utilização desses dois referenciais teóricos para o entendimento dos agravos à saúde mental e do sofrimento psíquico originados na execução da ação produtiva tornou-se necessária em razão das características da população atendida no espaço de atenção à saúde mental. Alguns trabalhadores apresentavam manifestações conflituosas que se expressavam nas ordenações da atividade onírica e nos vínculos institucionais; por isso, a análise das determinações contidas nos "espaços psíquicos comuns e partilhados" (Käes, 2005) figurava como foco da ação psicoterapêutica.

Em outras situações, a mobilização subjetiva permitida pela dialogicidade estabelecida no espaço de atenção à saúde mental possibilitava o enfrentamento do cotidiano institucional. Nessas situações, utilizaram-se as contribuições dejourianas para a análise do sofrimento no trabalho e consideravase que, "ao explicar a outrem o meu sofrimento, a minha relação com o trabalho, eu, perplexo, me ouço dizer coisas que eu não sabia, até tê-las dito" (Dejours, 1999b, p.176).

\section{Resultados e discussão}

\section{O discurso da violência no cotidiano de trabalho}

Alguns trabalhadores, que por quase uma década atuavam no sistema prisional sem o enfrentamento de rebeliões de maior extensão e violência, seguiam a designação de suas práticas de trabalho de modo rotineiro. Entre os atores institucionais, eram concebidos como os ordenadores e disciplinadores da população carcerária.
Constituía-se um espaço de temeridade em relação ao contato com esses trabalhadores, e, ao utilizar práticas disciplinares, eles relataram a condição de respeitabilidade e de domínio sobre a população carcerária.

Dessa forma, os comportamentos agressivos eram justificados e ganhavam legitimidade no discurso ideológico dos trabalhadores: faziam parte das exigências inerentes à organização do trabalho. A violência e a consequente humilhação podiam ser desvinculadas das perspectivas de injustiça e assujeitamento quando infligidas no contexto de "uma imposição de trabalho ou de uma submissão que lhes sublime a significação" (Dejours, 1999a, p.100).

Nos momentos de escuta dos trabalhadores, a violência é apontada como algo perturbador mesmo quando os ASPs não estão diretamente envolvidos, tal como nas ocorrências de violência entre os sentenciados. As situações com essa conformação mobilizam nos trabalhadores ansiedades paranóides, pois tornam evidentes o tênue limite entre as rígidas regras do estabelecimento prisional e a transgressão. Configura-se, então, a anomia e a decorrente desestabilização da estrutura discursiva que sustenta a "negação do risco" (Dejours, 1999a) no trabalho. A anomia se expressa na ruptura do sentimento de pertencimento a um grupamento social e até mesmo no reduzido nível de identificação entre os componentes de uma instituição (Garcia, 2006).

Como consequência de situações de anomia, destaca-se "a decadência e a desorganização da estrutura institucional dentro de um sistema social" (Meireles, 2004, p.70). Nesse sentido, as estratégias defensivas coletivas que sustentam a saúde mental perderiam sua coesão e o indivíduo se perceberia imerso em um espaço caracterizado "pelo apagamento das bordas entre a legalidade e a ilegalidade do ordenamento jurídico" (Catroli, 2009, p. 586). 
Em outras ocasiões, a percepção da anomia envolvia os ASPs recentemente integrados ao grupo de trabalhadores. Ao perceberem a distinção entre o trabalho prescrito, aprendido durante o período de formação profissional, e as reais condições de trabalho no sistema prisional, emergia uma condição desarmônica em que, conforme a proposição de Dejours (1992), “a energia pulsional que não acha descarga no exercício do trabalho se acumula no aparelho psíquico, ocasionando um sentimento de desprazer e tensão" (p. 123).

Como modo de dissuadir os ASPs que utilizavam a violência aberta para submeter os sentenciados, houve uma dinâmica de transferência da violência para elementos externos à instituição prisional. Assim, os familiares dos ASPs passaram a ser vitimizados pela rede relacional dos sentenciados. A violência direcionada pela ordenação dos sentenciados à família do trabalhador mobilizaria o enlutamento associado à possibilidade de perda dos objetos de amor e enfatizaria a iminência de tornar-se objeto da ação violenta, por isso, ansiedades constituídas por elementos "depressivos e paranóides" (Steiner, 1991) acometeriam os trabalhadores.

No espaço interno da instituição prisional, o histórico de violência como instrumento de trabalho é revisitado com a inversão de papéis institucionais, proporcionada pela tomada de ASPs como reféns em uma rebelião. Violência física aberta e violência simbólica se mesclam com características personalizadas para os ASPs tomados como reféns. Seus históricos de atuação disciplinar junto aos sentenciados são julgados nesse momento em que a ameaça de morte dolorosa é exemplificada com a prática de enrolar os ASPs em colchões e ameaçar incendiá-los.

Pode-se considerar que o sofrimento oriundo da relação com a violência receberá significações diferenciadas dependendo de seu modo operatório, do corpo que afetará, do espaço e do tempo que atravessará.

O trabalhador muitas vezes se vê impossibilitado de escapar de uma condição ameaçadora causada pelo trabalho, e com isso se acentuam as vivências com características paranóides. Essas vivências contam com a mobilização de defesas primitivas como a cisão, a idealização e a identificação projetiva (Steiner, 1991). Nessa perspectiva, a dinâmica do reconhecimento pela prática profissional - ou sua ausência - intensificaria ou reduziria as vivências ansiogênicas. Afirma-se que "do reconhecimento depende na verdade o sentido do sofrimento. Quando a qualidade do meu trabalho é reconhecida, também meus esforços, minhas angústias, minhas dúvidas, minhas decepções, meus desânimos adquirem sentido" (Dejours, 1999a, p. 34).

Partindo-se da análise da psicodinâmica do reconhecimento (Dejours, 1999a), concentraremos o questionamento em torno do modelo de progressão profissional na vigilância carcerária. Esta se caracteriza por escolhas da hierarquia institucional que não apresentam clareza quanto aos critérios avaliados para a progressão aos cargos mais elevados - ditos de confiança - e de melhor salário.

O modelo de progressão profissional desempenha papel importante no destino das vivências afetivas, pois pode reduzir a atividade ao sofrimento dela advindo e à submissão às ordenações discursivas das chefias. Essa perspectiva de prejuízo para a "psicodinâmica do reconhecimento" (Dejours, 1999a) implicaria a inscrição violentadora do trabalhador em uma perspectiva de ruptura do "contrato narcísico" (Kaës, 2005). De acordo com o autor, o contrato narcísico "está a serviço do fim que o indivíduo persegue por sua própria conta. Ele assegura a continuidade dos investimentos sobre si mesmo - corporal e 
psíquico - que sustentam em cada indivíduo o cumprimento de seu próprio fim" (Käes, 2005, p.173). Desse modo, a perspectiva de ruptura do contrato narcísico significaria a interrupção dos investimentos em si mesmo e, em consequência, a fragmentação da identidade do trabalhador.

\section{O estranhamento e a perturbação do espaço fora do trabalho}

As diversas formas de manifestação e utilização da violência conferem condições específicas para que o sofrimento psíquico surja entre os trabalhadores. Nessas ocasiões, eles podem vivenciar uma situação de estranhamento em relação ao trabalho, pois "a própria ação do homem converte-se num poder estranho a ele imposto, que o subjuga ao invés de ser por ele dominado" (Marx \& Engels, 1999, p.47). Assim, no espaço fora do trabalho, as dinâmicas institucionais podem contaminar as vivências afetivas e as relações de sociabilidade.

A contaminação do espaço fora do trabalho pelos mecanismos de poder e dominação (Foucault, 1987) implicaria a materialização da rotina institucional no limite domiciliar, modulando suas relações. Comportamentos com características compulsivas, tais como a verificação constante do fechamento de portas e janelas e a averiguação das condições de segurança da residência antes de iniciar o ciclo de sono são manifestações frequentes. Vigiar as relações pessoais dos filhos e manifestar intolerância frente à sua conduta são expressões da "disciplina dos corpos" (Foucault, 1987) que permeiam a tessitura familiar.

O reconhecimento, no discurso dos familiares, de gírias e expressões linguísticas utilizadas pelos sentenciados é percebido como a internalização dos valores e das normativas da população carcerária. A idealização da conduta dos familiares ilustra, no trabalhador, uma estruturação egóica arcaica que concebe "objetos bons idealizados mantidos bem separados de objetos maus persecutórios. Os impulsos primitivos do indivíduo são do mesmo modo cindidos, e ele dirige todo o seu amor para o objeto bom e todo o seu ódio contra o objeto mau" (Steiner, 1991, p. 330). Desse modo, a produção de violência seria um instrumento de ordenação de aspectos subjetivos para alguns trabalhadores. De acordo com Magalhães-Pinto (2006), "ser violento é resolver conflitos tendo como única estratégia o excesso (de força, palavras, poder)" (p. 248).

\section{As materializações da violência no corpo}

Nos atendimentos realizados no espaço de atenção à saúde mental, com frequência se apresentava a manifestação de fenômenos psicossomáticos. Ressalta-se que o sofrimento patogênico e a consequente desestruturação do quadro geral de saúde surgem, conforme a concepção dejouriana,

\begin{abstract}
"quando foram explorados todos os recursos defensivos, o sofrimento residual não compensado continua seu trabalho de solapar e começa a destruir o aparelho mental e o equilíbrio psíquico do sujeito, empurrando-o lentamente ou brutalmente para uma descompensação (mental ou psicossomática) e para a doença" (Dejours, 1994, p. 137).
\end{abstract}

Fernandes, Silvany Neto, Sena, Leal, Carneiro e Costa (2002) indicaram que queixas de adoecimento foram apresentadas por 91,6\% dos ASPs entrevistados em sua pesquisa na região metropolitana de Salvador (BA), e encontraram a manifestação de estresse persistente em $15,1 \%$ da população investigada. Fernandes et al. encontraram ainda a prevalência de distúrbios psíquicos 
menores entre $30,7 \%$ dos trabalhadores, o que apontaria maior possibilidade de degradação da saúde mental em comparação com professores, metalúrgicos, trabalhadores de processamento de dados e de hospitais.

A perturbação do sono é uma manifestação frequente entre esses trabalhadores. Além das dificuldades para iniciar o ciclo de sono, emergem manifestações oníricas aterrorizadoras sobre sua integridade física, sobre o coletivo dos trabalhadores e de seus familiares, situações em que o trabalhador do sistema prisional incorre em falhas que proporcionam a manifestação violenta dos sentenciados (ou fugas), ou, ainda, que podem levá-lo a práticas violentas extremas contra a população carcerária ou contra indivíduos com estes últimos identificados. A instituição prisional assume, então, dimensões intersubjetivas entranhadas no processo onírico e, nesse lugar denominado espaço onírico, é possível reconhecer as manifestações de sofrimento desses trabalhadores. O contato com a produção onírica de um grupo esclarece "as formações do inconsciente dos sujeitos, em seu encontro com o outro" (Kaës, 2005, p. 162).

O enlouquecimento é outra manifestação frequente na atividade onírica dos trabalhadores que se faz amedrontadora. No seu discurso, ficar chapado - expressão utilizada por eles para nomear o enlouquecimento - representaria o temor da fragmentação da identidade, portaria a perpetuação do cotidiano da violência pela precarização das funções do ego e instauraria o despertencimento do trabalhador em relação à ideologia defensiva do grupo.

Nessa condição, pode-se considerar que ficar chapado destituiria o trabalhador de um espaço partilhado, via estratégia defensiva, que lhe conferiria coesão à identidade. Ressalta-se também o enlouquecimento representado no seu discurso como atributo de fraqueza. O vínculo subjetivo representado pelo Eu onírico (Kaës, 2005) conferiria, ao trabalhador que enlouquecesse, a imagem deteriorada de um elemento que não resistiu ao embate contra os indivíduos corporificados como os representantes sociais da barbárie.

\section{A permeabilidade da violência nos espaços singulares e partilhados}

Vale destacar uma condição particular de sofrimento que envolve os trabalhadores que realizam a interlocução entre os sentenciados, seus familiares e outras vinculações afetivas da população carcerária. Nessa confluência de afetos, a leitura de cartas e a escuta de histórias durante as revistas nos dias de visitação constitui um processo de sensibilização dos trabalhadores e de redefinições das "representações sociais" (Joffe, 1995) relativas à vida precedente dos sentenciados recolhidos sob sua vigilância.

Perceber os diferentes "mecanismos psicossociais de apresentação/construção da realidade" (Xavier, 2002) contribui para modificar as referências de identidade e gera o questionamento da inteireza e da continuidade da organização psíquica individual, tanto do grupo quanto da instituição. Esses trabalhadores disponibilizam-se para o trabalho como mediadores de posições antagônicas; atuam como intermediários entre a condição desejante dos sentenciados, também representada pelos seus familiares, e a ordenação institucional, apresentada na função profissional desempenhada.

A posição de intermediário "permite fazer a mediação, a ponte entre duas ordens de realidade que possuem sua lógica própria, que são heterogêneas e que, em consequência, não podem ser reduzidas uma à outra" (Kaës, 2005, p.11). Nos corpos desses trabalhadores, dimensiona-se o espaço de 
produção do conflito pela regulamentação das relações sociais. Desses corpos habitados por uma funcionalidade disciplinar, derivam experiências subjetivas conflituosas. Deparar-se com as manifestações de violência confrontaria esses trabalhadores "não somente com o que há de estrangeiro no outro, mas, sobretudo, com o que surge em nós de desconhecido, de indiferenciado e de estranhamento inquietante" (Kaës, 2005, p.60). O contato com o estranho e o desconhecido é recoberto pela possibilidade de atração e repulsa (Leite, 2002), e pode implicar transformações "dos vínculos de sociabilidade, de estruturas de autoridade e de poder (...) que asseguravam a base narcísica de nosso pertencimento a um conjunto social. Elas comprometem os fundamentos de identidade" (Käes, 2005, p. 53).

Tomar ciência que se atua em um regime disciplinar que contribui para a perpetuação da violência atinge os fundamentos das formações de compromissos coletivos; assemelha-se, em alguns sentidos, às vivências e aos efeitos patológicos de ações ditatoriais. O silêncio sobre a dominação das imposições institucionais e as materializações de violência dos sentenciados impõem o "desaparecimento mudo" do trabalhador (Kaës, 2005).

A inconsistência da função intermediadora entre campos antagônicos - estado versus poder paralelo - articula o trabalhador com a instância do testemunho da violência e de sua propagação pelo silêncio. Estaria estabelecido o sofrimento originado pela "perturbação da fundação" e da "função instituinte", pelo entrave à "tarefa primária" do estabelecimento e pela instauração e manutenção do "espaço psíquico institucional" (Kaës, 1991). A perturbação da fundação e da função instituinte "priva os sujeitos de uma satisfação importante e debilita o espaço psíquico comum dos investimentos imaginários que vão sustentar a realização do projeto da instituição" (Kaës, 1991, p. 53). O entrave à função primária, que seria a ressocialização dos sentenciados pelas ações institucionais, não fornece "uma contribuição narcísica suficientemente trófica para a realização da tarefa" (Kaës, 1991, p. 55). Assim, questiona-se a legitimidade de alienar os sujeitos do poder de ressocializar do qual supostamente o Estado estaria investido.

Como representante do Estado, ressaltase no espaço subjetivo o esvaziamento da função que envolve o trabalhador por não estabelecer a função primária da instituição. Dado que na instauração do espaço psíquico institucional converge esse constrangimento, as fantasias de aniquilamento poderiam se inscrever no conceito de mudança catastrófica proposta por Bion (1970, p.92 citado por Kaës, 1991).

A mudança catastrófica expressa a mutação na estrutura institucional que ameaçaria o conjunto de vínculos intersubjetivos que conferem estabilidade ao sistema organizacional. Quando a estruturação defensiva mobilizada contra a mudança catastrófica não suporta as investidas da desefetivação do espaço psíquico institucional, ampliam-se as vivências paranóides dos "sujeitos singulares" (Kaës, 1991) pelo fato de se encontrarem destituídos dos vínculos intersubjetivos que sustentariam o pertencimento institucional.

\section{Considerações finais}

\section{O sofrimento psíquico e a atenção à saúde mental}

O reconhecimento dos prejuízos à saúde dos trabalhadores alocados na vigilância prisional leva a pensar sobre condições individualizadas como determinantes do sofrimento psíquico e da doença no espaço institucional. Queixas 
e sintomas do sofrimento psíquico poderiam, nessa abordagem, representar "vivências subjetivas de vulnerabilidade" (Jacques, 2002), imputando a doença apenas ao corpo que foi emprestado às forças que emolduram o processo de trabalho.

De acordo com Jacques, o diagnóstico do sofrimento psíquico desarticulado da repercussão do processo de trabalho na etiologia da doença contribui para a valoração social pejorativa do trabalhador e para prejuízos aos direitos previdenciários. Quando o sofrimento psíquico é tomado como não mais tolerável, o afastamento do trabalho se faz pela utilização de licençasprêmio e férias ainda não usufruídas pelo trabalhador. A utilização de licenças-saúde também é comum, mas implica o prejuízo a incorporações salariais destinadas aos trabalhadores engajados no processo laborativo da vigilância prisional. Nessa situação, os trabalhadores vivenciam uma dupla exclusão: da temporalidade da saúde e do amparo institucional qualificado pela integralidade do salário.

O tempo necessário para a elaboração de uma vivência violentadora, tal como uma rebelião, confere ao indivíduo o questionamento de suas ações laborativas e, em consequência, de seu pertencimento à organização de trabalho. Desse modo, depois de tomado como refém em uma rebelião, a prova de enraizamento e respeito ao grupo de trabalhadores foi apresentada como a imediata retomada das funções de contato com os sentenciados.

Batista e Codo (2002, p. 401) destacam que "o tempo, o que quer que seja, é objetivação/ subjetivação de uma espécie de métrica destinada a pôr ordem nos gestos". Assim, a ordenação dos gestos e afetos - com a rápida retomada do trabalho - em prol da manutenção da estrutura disciplinar e de vigilância é a objetivação do sofrimento ocultado em um corpo que encarna a eficiência da ação. O imperativo grupal da retomada das funções se sobrepõe ao sofrimento psíquico, e, com isso, a dominação se materializaria na morfologia do corpo em que as manifestações psicossomáticas acusam a negação do sofrimento em virtude das imposições institucionais.

É importante apontar um aspecto inerente à origem e ao significado do sofrimento que surge das implicações de uma prática profissional constituir, como se verificou neste relato de experiência profissional, um espaço individualizado para acolher o sofrimento do trabalhador. Esse aspecto refere-se à suspensão da determinação causal no espaço psíquico singular como formulador do sofrimento, pois sustenta-se em uma "relação isomórfica entre o sujeito e o grupo" (Kaës, 1991). Por esse motivo, não se deve circunscrever a análise do sofrimento no trabalho

"como se se cuidasse de uma causalidade fincada unicamente na história pessoal: o sofrimento atual nem sempre se resolve na história singular quando ele se finca na rede da vinculação. A questão da causa deve, pois, permanecer suficientemente em suspenso para que a diversidade das suas versões aflua e para que a sua sobredeterminação se manifeste" (Kaës, 1991, p.50)

O trabalho de acolhimento às demandas dos trabalhadores e a caracterização do sofrimento no trabalho demonstra que é possível a atenção em Psicologia se posicionar "como uma referência entre outras possíveis (...) num momento de perigo e risco para uma clientela que se encontra desalojada" (Schmidt, 2004, p. 9). Para a atenção a uma clientela que vivencia o desalojamento e o despertencimento, Schmidt propõe uma relação psicoterápica que sirva como contraponto à vivência ameaçadora e adversa que os indivíduos encontram no cotidiano. Esse trabalho seria pautado na contraposição 
ao ambiente e em relações conflituosas da instituição prisional. Seria um "lugar de repouso e suporte para o pensar, o brincar, o representar, o experimentar" (Schmidt, 2004 , p. 9). De acordo com França (2005), o acolhimento cria "um lugar de referência onde a desorganização e a reorganização podem coexistir em sua dialética enquanto possibilidade de reestruturação" (p. 50).

Lançadas as bases para a atenção ao trabalhador do sistema prisional, resta ainda discutir a resistência que subsiste à solicitação das instituições carcerárias para a atenção ao sofrimento dos trabalhadores. Essa resistência refere-se ao barramento do acesso aos serviços de atenção em saúde mental organizado por parte das chefias que coordenam os turnos de trabalho nas atividades de vigilância prisional. O impedimento da utilização do serviço de atenção em saúde mental pelos trabalhadores apresenta aspectos de dispositivos institucionais de assujeitamento. Destaca-se que a sujeição ao poder contribuiria para a degradação da saúde "quando os próprios trabalhadores são apenas objeto do controle organizacional sem que possam também exercê-lo, de modo suficiente, sobre as atividades que realizam e sobre o contexto de trabalho" (Sato, 2002, p. 35). Desse modo, a impossibilidade de exercer o poder de modelar o horário de trabalho e a alocação dos demais trabalhadores para que sua demanda afetiva fosse amparada no espaço de atenção em saúde mental constituiria uma intensa vivência de desamparo e dominação.

Na concepção de Bleger (1989), a resistência à constituição e à utilização de um serviço em Psicologia é indicativa das relações patológicas legitimadas na dinâmica institucional. O discurso dos trabalhadores poderia apresentar o dimensionamento coletivo das práticas de assujeitamento na instituição, pois os conteúdos ressignificados pela via da interpretação poderiam circular no espaço social e implicar a mobilização subjetiva de alguns trabalhadores. O serviço de atenção à saúde mental, portanto, poderia fundar-se como depositário de conflitos e disparador de questionamentos relativos às forças operantes na instituição. 


\section{Cassiano Ricardo Rumin}

Mestre em Ciências Médicas (FMRP/USP), Docente e Supervisor de Estágio em Saúde do Trabalhador nas Faculdades Adamantinenses Integradas (FAl), São Paulo - SP- Brasil.

E-mail: cassianorumin@fai.com.br

\section{Rafaela Atelli Nascimento Ferrari}

Especialista em Recursos Humanos e Psicologia Organizacional (UNITOLEDO), São Paulo - SP - Brasil.

E-mail: r_atelli@hotmail.com

\section{Gislaine Ilsiméia Faria Barros}

Psicóloga (FAI), São Paulo - SP - Brasil.

E-mail: gislainebarros2010@hotmail.com

\section{Willian Rogério Cardozo}

Psicólogo (FAl), São Paulo - SP - Brasil.

E-mail:wrog@hotmail.com

\section{Roseli Cavalhero}

Psicóloga (FAI), São Paulo - SP - Brasil.

E-mail: rcavalhero@dacal.com.br

Endereço para envio de correspondência:

Rua Esmeralda, n.166 - Bairro: Residencial Eldorado - Adamantina, São Paulo - SP - Brasil CEP: 17800-000

Recebido 20/3/2009, 1a Reformulação 10/3/2010, Aprovado 22/12/2010 


\section{Referências}

Antunes, R., \& Alves, G. (2004). As mutações no mundo do trabalho e na era da mundialização do capital. Educação e Sociedade, 25(87), 335-351.

Batista, A. S., \& Codo, W. (2002). O trabalho e o tempo. In W. Codo, \& M. G. Jacques (Orgs.), Saúde mental e trabalho: leituras (pp. 401-420). Petrópolis, RJ: Vozes.

Bleger, J. (1989). Psico-higiene e psicologia institucional. Porto Alegre: Artes Médicas

Braier, E. A. (2000). Psicoterapia breve de orientação analítica. São Paulo: Martins Fontes.

Catroli, V. S. (2009). Anonimato de vida e de morte: figuras contemporâneas de uma trama social violenta. Psicologia em Estudo, 14(3), 583-592.

Codo, W., \& Jacques, M. G. (2002). Saúde mental e trabalho: leituras. Petrópolis, RJ: Vozes.

Codo, W. (2004). O trabalho enlouquece? Um encontro entre a clínica e o trabalho. Petrópolis, RJ: Vozes.

Dejours, C. (1992). A loucura do trabalho: estudo de psicopatologia do trabalho. São Paulo: Cortez/Oboré,

Dejours, C. (1994). Psicodinâmica do trabalho: contribuições da escola dejouriana à analise da relação prazer, sofrimento e trabalho. São Paulo: Atlas.

Dejours, C. (1999a). A banalização da injustiça social. Rio de Janeiro: FGV.

Dejours, C. (1999b). Conferências brasileiras: identidade, reconhecimento e transgressão no trabalho. São Paulo: FUNDAP/FGV.

Fernandes, R. C. P., Silvany Neto, A. M., Sena, G. M., Leal, A. S., Carneiro, C. A. P., \& Costa, F. P. M. (2002). Trabalho e cárcere: um estudo com os agentes penitenciários da região metropolitana de Salvador, Brasil. Cadernos de Saúde Pública, 18(3), 807-816.

Foucault, M. (1987). Vigiar e punir: nascimento da prisão. Petrópolis, RJ: Vozes.

França, I. G. (2005). Reflexões acerca da implantação e funcionamento de um plantão de emergência em saúde mental. Psicologia: Ciência e Profissão, 25(1), 146-163.

García, J. M. R. (2006). Análisis comparativo de confiabilidad y validez de dos escalas de anomia. Revista Interamericana de Psicologia, 40(2), 193-204.

Herrmann, F. (2001). O divã a passeio: à procura da psicanálise onde não parece estar. São Paulo: Casa do Psicólogo.

Jacques, M. G. (2002). A doença dos nervos: uma expressão da relação entre saúde/doença mental. In W. Codo, \& M. G. Jacques (Orgs.), Saúde mental \& trabalho: leituras (pp. 98-111). Petrópolis, RJ: Vozes.

Joffe, H. (1995). Textos em representações sociais. Petrópolis, RJ: Vozes.

Kaës, R. (1991). A instituição e as instituições: estudos psicanalíti- cos. São Paulo: Casa do Psicólogo.

Käes, R. (2005). Os espaços psíquicos comuns e partilhados: transmissão e negatividade. São Paulo: Casa do Psicólogo.

Leite, D. M. (2002). O caráter nacional brasileiro. São Paulo: UNESP.

Magalhães-Pinto, R. (2006). O trabalho nos faz violentos: uma análise dos fatores relacionados com o comportamento violento do policial militar. In W. Codo (Org.), Por uma psicologia do trabalho: ensaios recolhidos (pp. 215-254). São Paulo: Casa do Psicólogo.

Marx, K., \& Engels, F. (1999). A ideologia alemã ( - Feuerbach). São Paulo: Hucitec.

Meireles, M. M. (2004). Anomia: ruptura civilizatória e sofrimento psíquico. São Paulo: Casa do Psicólogo.

Rumin, C. R. (2006). Sofrimento na vigilância prisional: o trabalho e a atenção em saúde mental. Psicologia: Ciência e Profissão, 26(4), 570-581.

Sato, L. (2002). Saúde e controle no trabalho: feições de um antigo problema. In W. Codo, \& M. G. Jacques (Org.), Saúde mental e trabalho: leituras (pp. 31-49). Petrópolis, RJ: Vozes.

Schmidt, M. L. S. (2004). Clínica psicológica, trabalho e desemprego: considerações teóricas. Cadernos de Psicologia Social do Trabalho, 7(1), 1-10

Steiner, J. (1991). O interjogo entre organizações patológicas e as posições esquizo-paranóide e depressiva. In E. B. Spillius (Org.), Melanie Klein: desenvolvimento da teoria e da técnica (pp. 329-347). Rio de Janeiro: Imago.

Xavier, R. (2002). Representação social e ideologia: conceitos intercambiáveis? Psicologia e Sociedade, 14(2), 18-47. 